\title{
Cationic Diiodo-Phosphoranides through Oxidative I-2 Addition to Tricyclic Phosphamethine Cyanines
}

\section{Cicac-Hudi, Mario}

2018-11-15

Cicac-Hudi , M , Schlindwein , S H , Feil , C M , Nieger , M \& Gudat , D 2018 , ' Cationic Diiodo-Phosphoranides through Oxidative I-2 Addition to Tricyclic Phosphamethine Cyanines ' , Zeitschrift für anorganische und allgemeine Chemie , vol. 644 , no. 21 , pp. 1304-1310 . https://doi.org/10.1002/zaac.201800264

http://hdl.handle.net/10138/324822

https://doi.org/10.1002/zaac.201800264

unspecified

acceptedVersion

Downloaded from Helda, University of Helsinki institutional repository.

This is an electronic reprint of the original article.

This reprint may differ from the original in pagination and typographic detail.

Please cite the original version. 


\title{
Cationic diiodo-phosphoranides through oxidative $\mathrm{I}_{2}$ addition to tricyclic phosphamethine cyanines
}

\author{
Mario Cicač-Hudi, ${ }^{[a]}$ Simon H. Schlindwein, ${ }^{[a]}$ Christoph M. Feil, ${ }^{[a]}$ Martin Nieger ${ }^{[b]}$ and Dietrich Gudat ${ }^{*[a]}$
}

Dedicated to Professor Dr. Werner Uhl on the occasion of his $65^{\text {th }}$ birthday.

\begin{abstract}
Reaction of methylene- and ethylene-bridged bisimidazolium salts with white phosphorus in the presence of $\mathrm{KO} t \mathrm{Bu}$ furnished moderate yields of tricyclic bis-imidazolio-phosphanide halides. Further oxidation of the products with one equivalent of $I_{2}$ gave bis-imidazolio-diiodophosphoranide iodides. All newly prepared compounds were characterized by analytical and spectral data and single-crystal XRD studies. DFT calculations provide evidence for substantial stabilization of cyclic bis-imidazolio-phosphanide cations by $\pi$-conjugation effects and suggest describing the bis-imidazoliodiiodophosphoranide cations as charge-transfer complexes of dicationic iodophosphines with iodide.
\end{abstract}

\section{Introduction}

The diverse electronic structure of phosphamethine cyanine derivatives remained a matter of scientific interest from the discovery of this class of compounds more than five decades ago. ${ }^{[1]}$ The extreme facets are readily illustrated by the cations $\mathbf{1}^{+},{ }^{[1]}$ which marks the earliest representative reported, and $\mathbf{2}^{+,},{ }^{[2]}$ which can be considered an analogue of $\mathbf{1}^{+}$resulting from formal replacement of the sulfur atoms by isoelectronic imido (NR) fragments (Scheme 1a). Cation $\mathbf{1}^{+}$was highlighted as the first isolable compound featuring multiple bonding to a lowcoordinate phosphorus atom, whereas the analogues $2^{+}$were pictured as double $\mathrm{NHC}$-adducts of an elusive $\mathrm{P}(\mathrm{I})$ cation (as symbolized by $\mathbf{2}^{\prime+}$ ) or, alternatively, as zwitterionic, bisimidazolio-substituted phosphanides. ${ }^{[3]}$ Despite these apparent differences, the bonding situation in both species can be consistently explained by a common approach invoking resonance between identical canonical structures $\left(\mathbf{A}, \mathbf{A}^{\prime}, \mathbf{B}\right.$ in Scheme 1b). ${ }^{[3],[4]}$

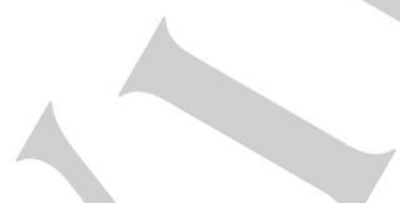

[a] Mario Cicač-Hudi, Simon H. Schlindwein, Christoph M. Feil, Prof. Dr. Dr. h. c. Dietrich Guda

Institute of Inorganic Chemistry

University of Stuttgart

Pfaffenwaldring 55, 70550 Stuttgart

Germany

E-Mail: gudat@iac.uni-stuttgart.de

[b] Dr. Martin Nieger,

Department of Chemistry

University of Helsinki

P.O Box 55, 00014 University of Helsinki,

Finland

Supporting information for this article is given via a link at the end of the document. a)
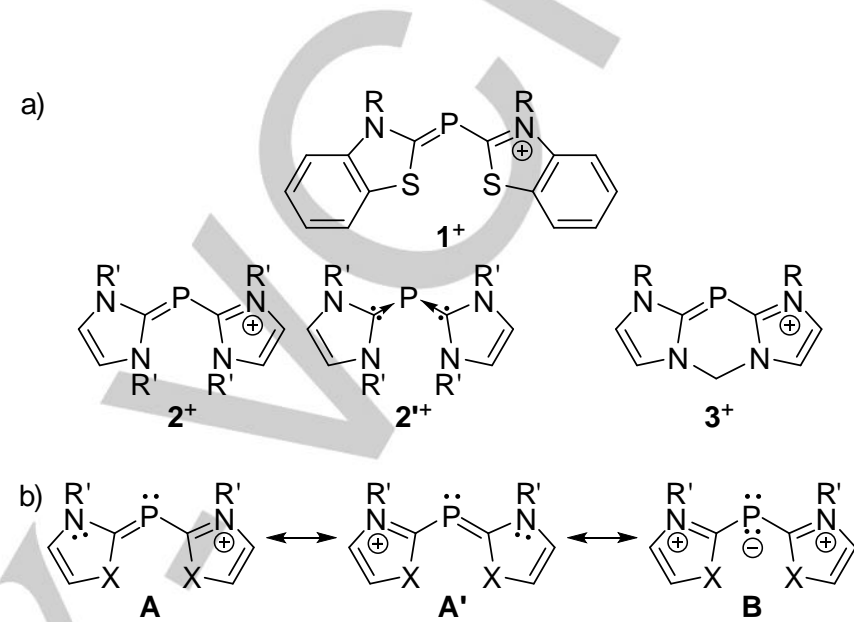

Scheme 1. a) Molecular structures of selected cationic phosphamethine cyanine derivatives $\mathbf{1}^{+}-\mathbf{3}^{+} ;$b) resonance description of the bonding in phosphamethine cyanine derivatives $\left(R=\right.$ alkyl; $R^{\prime}=$ alkyl, aryl; $\left.X=S, N R^{\prime}\right)$.

Cations $1^{+}$exhibit an almost planar $\pi$-electron system that is delocalized over the whole molecule and can be represented by considering the degenerate canonical structures $\mathbf{A}$ and $\mathbf{A}^{\prime}$ as dominant contributors to the total bonding description. Accordingly, two of four P-centered electrons not involved in $\mathrm{P}$ $\mathrm{C} \sigma$-bonding give rise to a lone-pair on phosphorus, while the other two are engaged in $\pi$-bonding to the adjacent carbon atoms, and the formal $\mathrm{P}-\mathrm{C}$ bond order comes close to a value of 1.5. Cations $2^{+}$display, in contrast, twisted molecular structures and elongated (in relation to $1^{+}$) P-C bonds, ${ }^{[3]}$ which indicate that $\pi$-delocalization across the phosphorus atom is obstructed. This situation is readily accounted for by assuming that the bonding is now dominated by the bis-imidazolio-phosphanide structure $\mathbf{B}$ featuring two lone-pairs on phosphorus and $\mathrm{P}-\mathrm{C}$ single bonds. The $\pi$-type interactions between the phosphorus atom and the adjacent imidazole rings (as exemplified by minor bonding contributions from structures $\mathbf{A}, \mathbf{A}^{\prime}$ ) involve both lone-pairs and were interpreted as hyperconjugative interactions. ${ }^{[5]}$ As a consequence, the $\mathrm{P}-\mathrm{C}$ bonds in $\mathbf{2}^{+}$are weaker than in $\mathbf{1}^{+}$but remain still stronger than pure single bonds. It was shown that the interfering steric influences can be circumvented by including both imidazole rings in a tricyclic structure as in $\mathbf{3}^{+}$which permits to return to a nearly planar alignment of the $\pi$-system and to reinstate the delocalization across the phosphorus atom. ${ }^{[6]}$ Intriguingly, the differences in structure and bonding between the twisted and planar phosphamethine cyanine derivatives $\mathbf{2}^{+}$ and $3^{+}$reflect on their chemical reactivity as nucleophiles. As expected in view of the dominance of canonical structure $\mathbf{B}$, cations $\mathbf{2}^{+}$are able to form complexes by binding simultaneously to two Lewis acids, ${ }^{[6]-[8]}$ and exhibit thus archetypal phosphanide- 
type behavior, while $3^{+}$seems to prefer binding a single Lewis acid via its $\pi$-type donor orbital. ${ }^{[6]}$

A certain P-centered nucleophilicity of phosphamethine cyanines is also evident from reports on the oxidation of cations of type $\mathbf{1}^{+}$ and $2^{+}$by sulfur to give dithiophosphinium salts. ${ }^{77[9]}$ Having recently demonstrated that neutral imidazolyl phosphinidenes $\mathbf{4}$, which contain a similar zwitterionic imidazolium-phosphanide substructure as $\mathbf{2}^{+}$, are readily oxidized to the di-iodides $\mathbf{5}$ (Scheme 2), ${ }^{[10]}$ we became interested in establishing if the cations $2^{+}$exhibit a similar reactivity. As the upshot of these studies, we report here on the isolation and characterization of the appropriate iodination products which can be formally addressed as diiodo-phosphoranides carrying an overall positive rather than the usual negative charge. Along with these results, we demonstrate that a previously reported protocol ${ }^{[5]}$ for a onestep synthesis of acyclic bis-imidazolio-phosphanides from elemental phosphorus, an imidazolium salt, and a base is readily extended to the synthesis of tricyclic cations like $3^{+}$if bisimidazolium salts are used as starting materials.

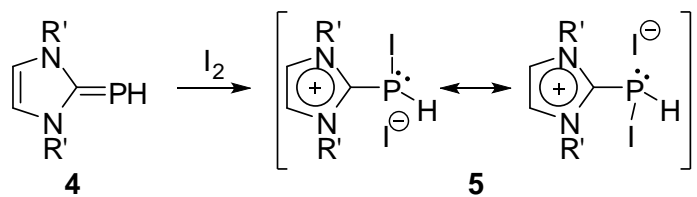

Scheme 2. lodine oxidation of imidazolyl-phosphinidenes $\left(\mathrm{R}^{\prime}=\right.$ alkyl, aryl)

\section{Results and Discussion}

Phosphamethine cyanine syntheses.

By analogy to the recently reported transformations ${ }^{[5]}$ of simple imidazolium salts (Scheme $3 a$ ), reactions of the bis-imidazolium salts $6 a\left[I_{2}\right]$ and $6 \mathrm{~b}\left[\mathrm{Br}_{2}\right]$ with white phosphorus in the presence of $\mathrm{KOtBu}$ in a molar ratio of $1: 1.25: 2$ in THF yield blends of several phosphorus-containing species. The ${ }^{31} \mathrm{P}\left\{{ }^{1} \mathrm{H}\right\} \quad \mathrm{NMR}$ spectra of reaction mixtures recorded after approx. $15 \mathrm{~min}$ reaction time displayed the signals of two main phosphoruscontaining products addressed as bifunctional phosphaalkenes 7a $\left(\delta^{31} \mathrm{P}-150.6,{ }^{1} J_{\mathrm{PH}}=165 \mathrm{~Hz}\right), 7 \mathbf{b}\left(\delta^{31} \mathrm{P}-153.1,{ }^{1} J_{\mathrm{PH}}=165 \mathrm{~Hz}\right)$ and tricyclic phosphamethine cyanine cations $8 \mathbf{a}^{+}\left(\delta^{31} \mathrm{P}-86.2\right)$ and $\mathbf{8} \mathbf{b}^{+}\left(\delta^{31} \mathrm{P}-89.6\right)$, respectively (Scheme $\left.3 b\right)$. In addition, a brownish precipitate consisting presumably of a mixture of inorganic salts and unidentified polyphosphorus species of unknown composition was formed. Crystalline salts $8 \mathrm{a}[\mathrm{l}]$ and $\mathbf{8 b}[\mathrm{Br}]$ could be isolated after work-up of the reaction mixtures and were fully characterized (see below); the best results so far were obtained when the work-up was conducted after approx. $24 \mathrm{~h}$ reaction time. Isolation of the bis-phosphaalkenes proved as yet unfeasible as these species were found to decay during this period to give rise to mixtures of further, as yet unidentified, follow-up products. Consequently, the assignment of $\mathbf{7 a , b}$ is mainly based on the analogy of the observed ${ }^{31} \mathrm{P} N M R$ parameters with those of previously known imidazolylidenephosphinidenes. ${ }^{[5]}$ An alternative constitution as phosphaalkenedecorated imidazolium salts $\mathbf{9 a , b}$ (Scheme 3b) cannot be completely ruled out based on the available spectral data, but seems unlikely under the specific reaction conditions.

a)<smiles></smiles>

b)

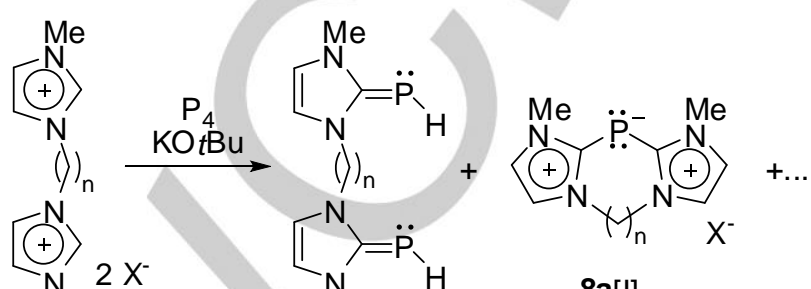$$
\mathrm{Me}
$$

$6 \mathrm{a}\left[\mathrm{l}_{2}\right]$ $6 \mathrm{~b}\left[\mathrm{Br}_{2}\right]$ $2 x$

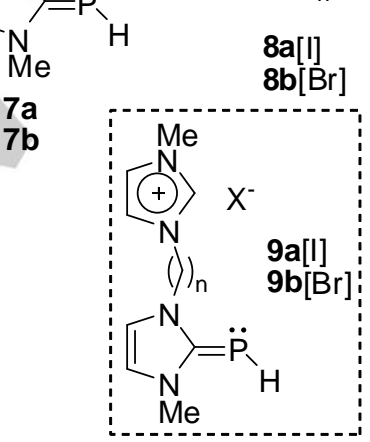

$8 \mathrm{a}[\mathrm{l}]$

Scheme 3. Three component reactions between a) monofunctional [5] and b) difunctional imidazolium salts, $\mathrm{P}_{4}$, and $\mathrm{KO} t \mathrm{Bu}\left(6 \mathrm{a}\left[\mathrm{l}_{2}\right]-9 \mathrm{a}[\mathrm{l}]: \mathrm{X}=\mathrm{I}, \mathrm{n}=1 ; 6 \mathrm{~b}\left[\mathrm{Br}_{2}\right]\right.$ $9 b[\mathrm{Br}]: \mathrm{X}=\mathrm{Br}, \mathrm{n}=2$ )

The spectral and structural data of $8 \mathrm{a}[\mathrm{l}]$ are a close match to those of the analogous salt $8 \mathrm{a}[\mathrm{OTf}]{ }^{[6]}$ which had previously been prepared from reaction of the appropriate bis-carbene with a triphosphenium salt. The spectral data of $\mathbf{8 b}[\mathrm{Br}]$ display likewise no peculiarities, but comparing the structural features of the cations in $\mathbf{8 a}[\mathrm{l}]$ and $\mathbf{8 b}[\mathrm{Br}]$ (Figure 1 ) is nonetheless enlightening. The central six- and seven-membered rings adopt boat and twist conformations, respectively. The torsional angles $\phi_{\text {tors }}$ between the CPC and the adjacent NCN planes are in case of $8 \mathrm{a}[1]$ $\left(19.7(1)^{\circ}\right.$ and $\left.17.5(1)^{\circ}\right)$ similar as in $\left.8 \mathrm{a}[\mathrm{OTf}]\right)^{[6]}\left(18.8^{\circ}\right.$ and $\left.19.1^{\circ}\right)$, but decrease in $8 \mathrm{~b}[\mathrm{Br}]$ to values of $8.0(2)^{\circ}$ and $15.2(2)^{\circ}$. At the same time, the valence angle at phosphorus rises from $92.1(1)^{\circ}$ in $8 \mathrm{a}[\mathrm{l}]$ to $104.0(2)^{\circ}$ in $\mathbf{8 b}[\mathrm{Br}]$. This value lies midway in the range of $99^{\circ}$ to $109^{\circ}$ reported ${ }^{[6]}$ for "planar" phosphamethine cyanine derivatives (with $\phi_{\text {tors }}<20^{\circ}$ ) that lack the constraints of a six-membered ring. Altogether, these features indicate that the expansion of the central ring seems to reduce angular strain and permits an even closer approach to a planar layout of the phosphamethine cyanine framework in $8 b[\mathrm{Br}]$ that would maximize $\pi$-delocalization across the phosphorus atom. If one considers, however, that the $\mathrm{P}-\mathrm{C}$ distances in $\mathbf{8 b}[\mathrm{Br}]$ (average $1.788(6) \AA$ ) are not significantly shorter than in $8 \mathrm{a}[\mathrm{l}]$ (average $1.792(2) \AA$ ) and lie in the range of $1.778(3)$ to $1.793(2) \AA$ reported by MacDonald et al. for various cations featuring the

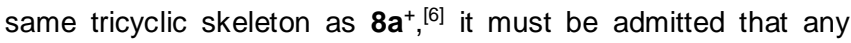


differences in the extent of $\pi$-conjugation are presumably small and their impact on structural features is negligible.

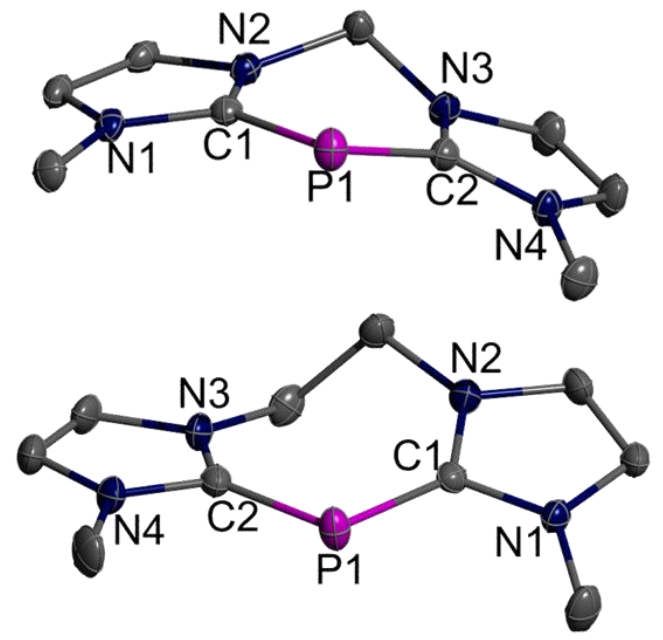

Figure 1. Molecular structures of the cations in crystalline $8 \mathrm{a}[\mathrm{l}]$ (top) and $8 \mathrm{~b}[\mathrm{Br}]$ (bottom). Thermal ellipsoids are drawn at the $50 \%$ probability level and hydrogen atoms were omitted for clarity. Selected distances $[\AA]$ and angles $\left[^{\circ}\right]$ : 8a+: P1-C2 1.790(2), P1-C1 1.793(3), N1-C1 1.359(3), N2-C1 1.353(3), N3C2 1.354(3), N4-C2 1.351(3), C2-P1-C1 92.12(11); 8b+: P1-C2 1.783(4), $\mathrm{P} 1-\mathrm{C} 1$ 1.792(3), C2-N3 1.362(5), C2-N4 1.363(4), N2-C1 1.353(4), C1-N1 1.353(4), C2-P1-C1 104.04(16).

\section{Phosphamethine cyanine diiodides}

Reactions of $\mathbf{8} \mathrm{a}[\mathrm{l}]$ and $\mathbf{8 b}[\mathrm{Br}]$ with equimolar amounts of $\mathrm{I}_{2}$ furnished highly moisture sensitive cyclic diiodo phosphoranides $10 \mathrm{a}[\mathrm{I}]$ and $10 \mathrm{~b}[\mathrm{Br}]$ (Scheme 4) in near quantitative yield (according to ${ }^{31} \mathrm{P}$ NMR spectroscopic reaction monitoring).

Even if bis-imidazolio-diodophosphoranides are unprecedented, an analogous dichloride $\mathbf{1 1}$ was synthesized via a different approach, viz. Lewis-acid promoted substituent scrambling of $\mathrm{NHC}^{-\mathrm{PCl}_{3}}$ (NHC = imidazolyl-ylidene fragment). ${ }^{[11]}$ Moreover, action of a sterically demanding $\mathrm{NHC}$ on an imidazoliodichlorophosphine cation $\mathrm{NHC}-\mathrm{PCl}_{2}{ }^{+}$furnished dichloride 12 featuring both 2- and 4-imidazolio-substituents. ${ }^{[12]}$

Both products $10 \mathrm{a}[\mathrm{I}]$ and $10 \mathrm{~b}[\mathrm{X}](\mathrm{X}=\mathrm{Br}$ or I) were isolated in high yield. Their identity was established by analytical and spectral data and, after fractional recrystallization, confirmed by single-crystal XRD studies. While characterization of $10 \mathrm{a}[\mathrm{I}]$ was straightforward, the case of $10 \mathrm{~b}[\mathrm{X}]$ requires some comments. Even if the presence of different halogen atoms in the starting materials implies that the reaction product must likewise exhibit a mixed composition, the analytical composition of a product $10 \mathrm{~b}[\mathrm{l}]$ isolated after fractional crystallization suggests that segregation of the halogen atoms leading to enrichment of iodine atoms in the crystalline material (and, accordingly, bromine atoms in the mother liquor) had occurred. The segregation hypothesis was backed by the observation that the ${ }^{31} \mathrm{P}$ NMR chemical shifts moved continuously to slightly more negative values when the presumed iodine-content increased, and was corroborated by the crystallographic study which revealed that the structure could readily be successfully solved and refined by assuming the exclusive presence of iodine in the sample. Nonetheless, some problems associated with the anisotropic displacement parameters of the iodine atoms (see Figure 2 and $\mathrm{ESI}$ ) suggest that the segregation is presumably not quantitative and the crystalline material still contains minor amounts (within the error limits of the elemental analysis) of bromine atoms. Further resolution of this issue and attempts to quantify the residual bromine content were impeded by the high sensitivity of the samples.
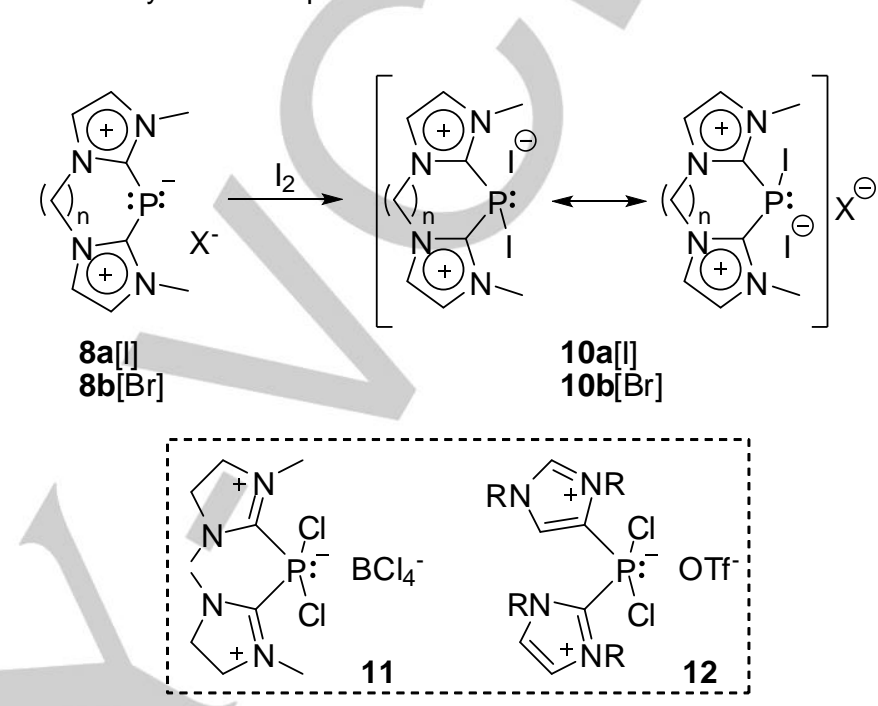

Scheme 4. lodine oxidation of cyclic bis-imidazolio-phosphanide halides $8 \mathrm{a}[\mathrm{l}]$ and $8 \mathrm{~b}[\mathrm{Br}]$ and molecular constitution of previously reported salts $11{ }^{[11]}$ and 12 [12] $\left(\mathrm{R}=2,6-\mathrm{Pr}_{2} \mathrm{C}_{6} \mathrm{H}_{5}\right)$ containing bis-imidazolio-dihalidophosphoranide cations. Note that $10[X]$ (with $X \neq I$ ) may in principle form two distinguishable isomers only one of which is shown for clarity $(8 \mathrm{~B}[\mathrm{I}], \mathbf{1 0 a}[\mathrm{l}]: \mathrm{X}=\mathrm{I}, \mathrm{n}=1 ; \mathbf{8 b}[\mathrm{Br}]$, $10 \mathrm{~b}[\mathrm{Br}]: \mathrm{X}=\mathrm{Br}, \mathrm{n}=2$ ).

Reactions of acyclic phosphamethine cyanines were, in contrast to those of $\mathbf{8 a}, \mathbf{b}[\mathrm{X}]$, unselective and furnished, according to ${ }^{31} \mathrm{P}$ NMR spectroscopic assays, complex product mixtures. Even if the spectroscopic data suggested that acyclic analogues of $10 \mathrm{a}, \mathrm{b}[\mathrm{X}]$ might be present, neither of these could be positively identified or isolated, and further elucidation of these reactions was postponed.

The ${ }^{1} \mathrm{H}$ and ${ }^{13} \mathrm{C}$ NMR spectra of $10 \mathrm{a}[\mathrm{I}]$ and $10 \mathrm{~b}[\mathrm{I}]$ indicate that the organic framework had survived the iodination unchanged. The ${ }^{31} \mathrm{P}$ NMR chemical shifts (10a[l]: $-146.8 \mathrm{ppm} ; \mathbf{1 0 b}[\mathrm{l}]:-130.4$ ppm) range intermediate between those of diiodides $5^{[10]}$ that had been obtained by iodination of imidazolyl-phosphinidenes 4 with $\mathrm{N}$-alkyl $\left(\delta^{31} \mathrm{P}-175\right.$ to -183$)$ or $\mathrm{N}$-aryl substituents $\left(\delta^{31} \mathrm{P}-127\right.$ to -138$)$, respectively. Crystals of $10 \mathrm{a}[\mathrm{I}]$ contain pairs of bisimidazolio-diiodo-phosphoranide ions with a net positive charge and iodide anions featuring $\mathrm{P} \cdots \mid$ contacts (P1-|1A 3.8483(8) $\AA$ ) slightly shorter than the sum of the van-der-Waals radii $(3.94$ $\AA ;:[13]$ Figure 2, top). Crystalline $10 \mathrm{~b}[\mathrm{l}]$ was identified as a solvate consisting of an array of two crystallographically independent bis-imidazolio-diiodo-phosphoranide cations with very similar metrics, the appropriate number of isolated iodide anions ( $\mathrm{P} \cdots \mid$ $5.777(2) \AA$ ), and one molecule of acetonitrile per ion pair (Figure 2 , bottom). One of the solvent molecules is disordered, and one 
iodine atom in each cation $(I(3)$ and $I(6)$, respectively) exhibits unusual thermal ellipsoids which point to a disorder resulting from a partial occupation of these positions by bromine atoms.
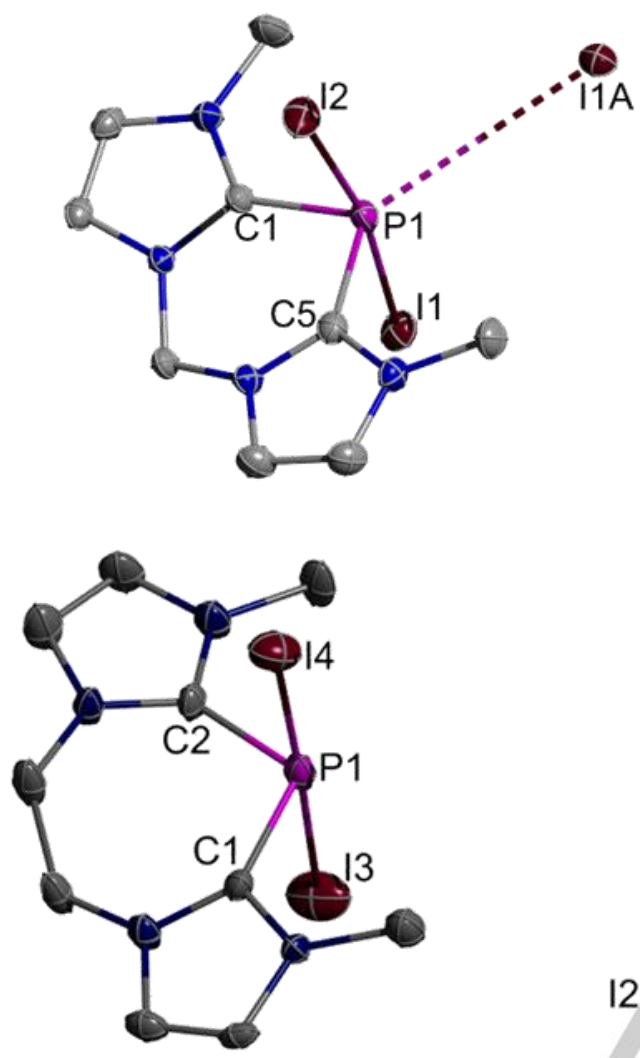

Figure 2. Molecular structure of ion pairs in crystalline $10 \mathrm{a}[\mathrm{l}]$ (top) and $10 \mathrm{~b}[\mathrm{l}]$ (bottom; only one of two crystallographically independent cations and the closest anion displayed). Thermal ellipsoids are drawn at the $50 \%$ probability level and hydrogen atoms were omitted for clarity. Selected distances $[\AA]$ and angles $\left[{ }^{\circ}\right]$ (data in brackets refer to the second independent cation in $10 \mathrm{~b}[\mathrm{I}]$ ): 10a[1]: P1-C1 1.809(3), P1-C5 1.809(3), P1-I1 2.7201(9), P1-I2 2.8292(9),

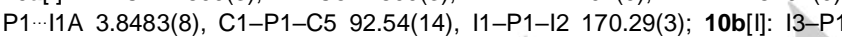
2.787(3) [15-P2 2.654(3)], I4-P1 2.682(3) [16-P2 2.663(3)], P1-C2 1.819(8) [P2-C3 1.813(8)], P1-C1 1.820(8) [P2-C4 1.816(9)], C2-P1-C1 104.3(4) [C3-P2-C4 104.5(4)], 14-P1-I3 178.04(9) [15-P2-16 171.11(10)].

The phosphorus atoms in $\mathbf{1 0 \mathbf { a } ^ { + }}$ and $\mathbf{1 0 \mathbf { b } ^ { + }}$ adopt pseudo trigonalbipyramidal coordination geometries in which the C2-carbon atoms of the imidazolyl units occupy equatorial and the iodine atoms axial positions. The remaining equatorial site is presumably occupied by a lone-pair of electrons. All P-C distances in $\mathbf{1 0 a}, \mathbf{b}[\mathbf{l}](1.809(3)$ to $1.820(8) \AA$ ) are identical within experimental error and marginally longer than in the phosphamethine cyanines $8 \mathrm{a}[\mathrm{l}]$ and $8 \mathrm{~b}[\mathrm{Br}](1.783(4)$ to $1.793(3)$ $\AA$ ). The central six- and seven-membered rings display analogous boat and twist conformations as $8 \mathrm{a}[\mathrm{l}]$ and $\mathbf{8 b}[\mathrm{Br}]$. The deviation from planarity of the bis-imidazolio-phosphanide units (as expressed by torsional angles between CPC and adjacent NCN planes of $9.0(2)$ and $9.4(1)^{\circ}$ in $10 \mathrm{a}[\mathrm{l}]$ and $7.3(4)$ to $13.3(4)^{\circ}$ in $\mathbf{1 0 b}[\mathrm{l}]$ ) is slightly lower than in $\mathbf{8 a}[\mathrm{l}]$ and $\mathbf{8 b}[\mathrm{Br}]$. In contrast, the
C-P-C angles (10a[l]: 92.54(14) ${ }^{\circ}, 10 \mathrm{~b}[\mathrm{l}]:$ 104.3(4), 104.5(4) $\left.)^{\circ}\right)$ are similar as in $\mathbf{8 a}[\mathrm{l}]$ and $\mathbf{8 b}[\mathrm{Br}]$, respectively, indicating that the chelating bis-imidazolyl-units support rather fixed bite angles. The P-I distances $(2.654(3)$ to $2.829(1) \AA$ ) exceed generally standard values for single bonds $\left(2.49-2.493 \AA^{[14]}\right)$, and their absolute values and variance match the data found for 5 (2.611(1) to $3.006(1) \AA{ }^{[10]}$ ). The two $\mathrm{P}-\mathrm{I}$ distances in an individual cation exhibit rather modest inequalities, deviations not exceeding $11 \mathrm{pm}$ as compared to $11-40 \mathrm{pm}$ in case of 5 ${ }^{[10]}$. Regardless of minor individual differences, the cations in $10 \mathrm{a}[\mathrm{I}]$ and $10 \mathrm{~b}[\mathrm{I}]$ and the zwitterionic phosphoranides 5 [10] exhibit close similarities in both molecular shapes and metrical parameters which suggests that the electronic structures in both types of compounds should likely be closely akin. Embarking on this argument, we describe the cationic bis-imidazolio-diiodophosphoranide unit in $10 \mathrm{a}[\mathrm{l}]$ and $\mathbf{1 0 b}[\mathrm{l}]$ like $5^{[10]}$ as chargetransfer complex of a dicationic bis-imidazolio-substituted iodophosphine with an iodide anion. Salts of such dicationic phosphines with P-phenyl or P-alkoxy-substituents and tricyclic structures based on both six- and seven-membered rings have recently been accessed through double alkylation of cyclic bisimidazolyl-phosphines [15] or condensation of bis-imidazolium salts with suitable phosphorus electrophiles, ${ }^{[16]}$ respectively.

\section{Computational studies}

Further substantiation of the proposed $\pi$-delocalization effects in the cations $\mathbf{8}^{+}$and the description of $\mathbf{1 0}^{+}$as charge-transfer complexes of dicationic phosphines with iodide was derived from DFT studies. The calculations were carried out at the same theoretical level that had previously been applied ${ }^{[10]}$ in a computational study on $\mathbf{5}$ (RI-B3LYP-D3BJ/def2-tzvp) under inclusion of solvation effects by using the COSMO model with the solvent parameters for acetonitrile. Energy optimization of the geometry of phosphamethine cyanines $\mathbf{8 a}, \mathbf{b}[\mathbf{l}]$ (for better comparability, iodide ions were used in all computations) and iodination products $10 \mathrm{a}, \mathrm{b}[\mathrm{l}]$ furnished molecular structures that are in close agreement with the observed ones and reproduce in particular the ionic nature of all compounds. Calculations on isolated cations $\mathbf{8} \mathbf{a}, \mathbf{b}^{+}$and $\mathbf{1 0 a}, \mathbf{b}^{+}$indicated that the neglect of the counter ions had only minor impact on both the metrics and the outcome of natural population analyses, ${ }^{[17]}$ and we will therefore focus exclusively on the isolated cations in order to simplify the further discussion.

The molecular structures located after symmetry-unrestricted energy optimization of all species included in the calculations are characterized by the presence of symmetrical tricyclic frameworks which deviate not significantly from ideal $C_{2^{-}}$(for 6 membered central rings) or $C_{2}$-symmetry (for 7-membered central rings) and exhibit essentially equal $\mathrm{P}-\mathrm{C}$ distances (see Table 1). The $P-I$ bonds in $\mathbf{1 0 b ^ { + }}$ are as well equal whereas in case of $10 a^{+}$the $\mathrm{P}-\mathrm{I}$ bond occupying the flagpole position in the boat-shaped six-membered central ring is by approx. $10 \mathrm{pm}$ shorter than the remaining one, matching a similar inequivalence observed experimentally. A relaxed potential energy scan on $\mathbf{1 0 \mathbf { b } ^ { + }}$ disclosed that desymmetrization of the I-P-I unit is easily feasible at low energetic cost (inducing a difference of $50 \mathrm{pm}$ between both $\mathrm{P}-\mathrm{I}$ distances requires merely an input of $<0.8$ 
kcal $\mathrm{mol}^{-1}$ ). Repeating the same potential energy scan on an isolated molecule in the gas phase revealed that the $\mathrm{P}-\mathrm{I}$ distances are shorter (2.776 $\AA$ vs. $2.813 \AA$ with solvation effects included) and less compliant to desymmetrization (inducing a difference in $\mathrm{P}-\mathrm{I}$ distances of $50 \mathrm{pm}$ now requiring an energy input of $2.2 \mathrm{kcal} \mathrm{mol}^{-1}$ ), but the deformation energy remains still sufficiently small that even weak external forces like crystal packing effects may induce substantial geometric distortions. Similar results have recently been obtained for the zwitterions 5 and suggest describing the bonding in the IPI-unit as a 3-center4-electron bond (see below). ${ }^{[10]}$ Moreover, the susceptibility of the $\mathrm{P}-\mathrm{I}$ distances in $\mathbf{1 0} \mathbf{a}, \mathbf{b}^{+}$to the influence of dielectric media allows one as well to rationalize the large deviations between computed and measured bond lengths.

The natural bond order (NBO) analyses ${ }^{[17]}$ of the computed electron density of phosphamethine cyanine cations $\mathbf{8 a}, \mathbf{b}^{+}$ identified, as expected, the polar symmetrical bis-imidazoliophosphanide assembly as the leading resonance structure for both cations. Calculated distances and Wiberg bond indexes (WBI, see Table 1) suggest pronounced equalization of formal single and double bonds in the imidazole rings, which can be traced to cyclic $6 \pi$-delocalization and is in accord with the commonly acknowledged aromatic character of the imidazolium unit. In addition, the WBI for the PC bonds are also considerably larger as expected for single bonds and point to the presence of $\pi$-conjugation across the phosphorus atom. The additional bonding contribution results, according to an analysis of $2^{\text {nd }}$ order perturbational interactions between individual NBOs, from electron donation out of the p-type ("out-of-plane") lone-pair on the phosphorus atom into adjacent $\pi^{*}(\mathrm{CN})$ NBOs on both imidazolium units and can be characterized as $p(P) \rightarrow \pi^{*}\left(\mathrm{C}_{3} \mathrm{~N}_{2}\right)$ hyperconjugation. As expected, the second ("in-plane") lone-pair on phosphorus remains essentially unaffected by the $\pi$ interaction. The stabilization by $(\mathrm{P}) \rightarrow \pi^{\star}\left(\mathrm{C}_{3} \mathrm{~N}_{2}\right)$ hyperconjugation was estimated by means of an NBO deletion analysis as 58.3 $\mathrm{kcal} / \mathrm{mol}$ for $\mathbf{8} \mathbf{a}^{+}$and $57.2 \mathrm{kcal} / \mathrm{mol}$ for $\mathbf{8} \mathbf{b}^{+}$, indicating that $\pi$ conjugation contributes substantially to the bonding energy but is independent of the ring size. An analogous bonding description with comparable energetic implications had previously been established by MacDonald et al. ${ }^{[6]}$ for tricyclic phosphamethine cyanines with central six-membered rings.

In case of $10 \mathbf{a}, \mathbf{b}^{+}$, the leading NBO resonance structures were identified as the expected ion pairs consisting of a bisimidazolio-iodophosphine dication and an iodide anion. The WBIs and $2^{\text {nd }}$ order perturbation energies report the presence of an even stronger $\pi$-delocalization in the imidazolio-units than in $\mathbf{8} \mathbf{a}, \mathbf{b}^{+}$whereas the $\mathrm{P}-\mathrm{C}$ bonds attain essentially the character of polar single bonds. The bonding in the semi-ionic IPI-units of the leading NBO structures is characterized by strong $\mathrm{n}\left(\mathrm{I}^{-}\right) \rightarrow \sigma^{*}(\mathrm{P}-\mathrm{I})$ charge transfer contributions which provide according to an NBO deletion analysis an energetic stabilization of $59.9\left(\mathbf{1 0 a}^{+}\right)$and $88.0\left(\mathbf{1 0 b}^{+}\right) \mathrm{kcal} \mathrm{mol}^{-1}$, respectively. These effects are in accord with the aforementioned representation of the I-P-I-interactions as delocalized 3-center-4-electron bonds that can be represented by resonance between two bond/no-bond canonical formulae (I-PR $\mathrm{I}^{-} \leftrightarrow \mathrm{I}^{-} \mathrm{R}_{2} \mathrm{P}-\mathrm{I}, \mathrm{R}=$ imidazolium-substituent). The distances and WBls suggests that ionic and covalent contributions are in case of $\mathbf{1 0 \mathbf { b } ^ { + }}$ nearly symmetrically distributed over both $\mathrm{P}-\mathrm{l}$-bonds whereas the covalent character is in $\mathbf{1 0 \mathbf { a } ^ { + }}$ accumulated in the bond to the iodine atom in the "flagpole"position. It should be noted that this imbalance does not point to a principal difference in the bonding of $10 \mathbf{a}, \mathbf{b}^{+}$but arises presumably from conformational constraints in the six-

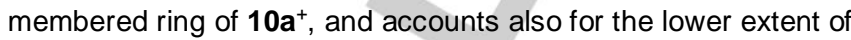
$\mathrm{n}\left(\mathrm{I}^{-}\right) \rightarrow \sigma^{\star}(\mathrm{P}-\mathrm{l})$ charge transfer in this cation.

Table 1. Selected distances (calculated at theCOSMO-RI-B3LYPD3BJ/def2-tzvp level) and Wiberg bond indexes (WBI, from NBO analyses of PCM-B3LYP-D3BJ/def2-tzvp densities) for $\mathbf{8} \mathbf{a}, \mathbf{b}^{+}$and $\mathbf{1 0 a}, \mathbf{b}^{+}$(see experimental section for further details).

\begin{tabular}{|c|c|c|c|c|}
\hline & $8 a^{+}$ & $8 b^{+}$ & $10 a^{+}$ & $10 b^{+}$ \\
\hline \multicolumn{5}{|l|}{ Distances } \\
\hline$P-C 2^{[a, b]}$ & 1.791 & 1.792 & 1.827 & 1.819 \\
\hline $\mathrm{C} 2-\mathrm{N}^{[a, b]}$ & 1.354 & 1.359 & 1.343 & 1.346 \\
\hline $\mathrm{N}-\mathrm{C} 4,5^{[a, b]}$ & 1.386 & 1.384 & 1.375 & 1.374 \\
\hline C4-C5[b] & 1.352 & 1.350 & 1.357 & 1.358 \\
\hline$P-1$ & -- & -- & $\begin{array}{l}2.750 \\
2.946\end{array}$ & $\begin{array}{l}2.813 \\
2.812\end{array}$ \\
\hline $\mathrm{P}-\mathrm{l}_{\text {avg }}{ }^{[\mathrm{a}]}$ & & -- & 2.848 & 2.813 \\
\hline \multicolumn{5}{|c|}{ Wiberg bond indexes (WBI) } \\
\hline $\mathrm{P}-\mathrm{C} 2^{[a, b]}$ & 1.12 & 1.13 & 0.91 & 0.92 \\
\hline $\mathrm{C} 2-\mathrm{N}[\mathrm{a}, \mathrm{b}]$ & 1.23 & 1.22 & 1.27 & 1.27 \\
\hline $\mathrm{N}-\mathrm{C} 4,5^{[a, b]}$ & 1.12 & 1.13 & 1.16 & 1.17 \\
\hline C4-C5[b] & 1.67 & 1.66 & 1.62 & 1.61 \\
\hline$P-1$ & -- & -- & $\begin{array}{l}0.59 \\
0.22\end{array}$ & $\begin{array}{l}0.50 \\
0.50\end{array}$ \\
\hline
\end{tabular}

[a] average for all bonds of this type. [b] C2, C4, C5 denote the position of carbon atoms in the imidazole rings.

\section{Conclusions}

Reaction of $\mathrm{P}_{4}$ with alkylidene-bridged bis-imidazolium salts provides a new access route to tricyclic bis-imidazoliophosphanide cations with different sizes of the central ring. lodine oxidation of these species is more selective than in case of acyclic bis-imidazolio-phosphanide cations and furnishes isolable bis-imidazolio-diiodophosphoranide ions. Computational and crystallographic studies suggest formulating these species as charge transfer complexes of dicationic bis-imidazoliophosphines with iodide. Apart from their interesting bonding situation, the prospect to utilize the covalent $\mathrm{P}-\mathrm{I}$ functionality in 
substitution reactions and exchange the remaining two, or even all three, iodides by weakly coordinating anions makes these species interesting starting materials for the preparation of new polycationic phosphines.

\section{Experimental Section}

\section{General conditions}

All manipulations were carried out in an atmosphere of dry argon or nitrogen using standard vacuum line techniques. Solvents were dried prior to use by common procedures. NMR spectra were recorded on Bruker Avance $400\left({ }^{1} \mathrm{H} 400.1 \mathrm{MHz},{ }^{31} \mathrm{P} 161.9 \mathrm{MHz},{ }^{13} \mathrm{C} 100.6 \mathrm{MHz}\right)$ or Avance $250\left({ }^{1} \mathrm{H} \quad 250.1 \mathrm{MHz},{ }^{31} \mathrm{P} \quad 101.2 \mathrm{MHz},{ }^{13} \mathrm{C} \quad 62.8 \mathrm{MHz}\right)$ spectrometers at $303 \mathrm{~K}$. Chemical shifts were referenced to ext. TMS $\left({ }^{1} \mathrm{H}\right.$ $\left.{ }^{13} \mathrm{C}\right)$ or $85 \% \mathrm{H}_{3} \mathrm{PO}_{4}\left(\equiv=40.480747 \mathrm{MHz},{ }^{31} \mathrm{P}\right)$. FT-IR spectra were recorded on a Thermo Scientific Nicolet iS5 spectrometer equipped with an iD5 ATR unit. Elemental analyses were determined with an Elementar Micro Cube elemental analyzer. Imidazolium salts $4 \mathrm{a}[\mathrm{I}] 2$ and $\mathbf{4 b}[\mathrm{Br}]_{2}$ were synthesized according to a modified procedure by Guo, Zhao et al. ${ }^{[18]}$.

Synthesis of $8 \mathrm{a}[\mathrm{l}]$ : A mixture of bis-imidazolium salt $4 \mathrm{a}[\mathrm{l}]]_{2}(5.00 \mathrm{~g}$ $11.6 \mathrm{mmol})$, KOtBu $(2.60 \mathrm{~g}, 23.1 \mathrm{mmol})$ and $\mathrm{P}_{4}(1.79 \mathrm{~g}, 14.5 \mathrm{mmol})$ was dispersed in THF $(200 \mathrm{~mL})$, and the resulting slurry was agitated by magnetic stirring for $24 \mathrm{~h}$. The liquid phase adopted an orange color, and a brown precipitate formed. The solids were separated by filtration through a G4 frit, and washed with THF $(2 \times 50 \mathrm{~mL})$. The remaining residue was dispersed in acetonitrile $(150 \mathrm{~mL})$, and the dispersion was filtered of through a G4 frit loaded with a pad of Celite. Concentration of the filtrate and fractional crystallization at $-15^{\circ} \mathrm{C}$ furnished $1.12 \mathrm{~g}$ (3.36 $\mathrm{mmol}$, yield $29 \%$ with respect to $4 \mathrm{a}\left[\mathrm{Il}_{2}\right)$ of $\mathbf{8 a}[\mathrm{l}]$ as colorless, crystalline solid. Single crystals suitable for an XRD study were obtained from a concentrated acetonitrile solution. $-{ }^{1} \mathrm{H}$ NMR $(400 \mathrm{MHz}): \delta==7.28(\mathrm{~m}, 2$ $\left.\mathrm{H}, \mathrm{HC}=\mathrm{CHNCH}_{2}\right), 7.21\left(\mathrm{t}, 2 \mathrm{H},{ }^{4} \mathrm{JPH}_{\mathrm{PH}}={ }^{3} \mathrm{JHH}_{\mathrm{HH}}=1.7 \mathrm{~Hz}, \mathrm{HC}=\mathrm{CHNCH}_{2}\right), 5.94$ $\left(\mathrm{d}, 2 \mathrm{H},{ }^{4} \mathrm{~J}_{\mathrm{PH}}=0.9 \mathrm{~Hz}, \mathrm{CH}_{2}\right), 3.53\left(\mathrm{~d}, 6 \mathrm{H},{ }^{4} \mathrm{JPH}_{\mathrm{PH}}={ }^{3} \mathrm{JHH}_{\mathrm{HH}}=1.1 \mathrm{~Hz}, \mathrm{CH}_{3}\right)$. ${ }^{31} \mathrm{P}$ NMR (161.9 MHz): $\delta=-84.8 .-{ }^{15} \mathrm{~N}$ NMR $(40.56 \mathrm{MHz}): \delta=-222.3$, 222.8. $-{ }^{13} \mathrm{C}\left\{{ }^{1} \mathrm{H}\right\}$ NMR $(100.5 \mathrm{MHz}): \delta=161.9\left(\mathrm{~d},{ }^{1} \mathrm{JPC}=73.6 \mathrm{~Hz}, \mathrm{PC}\right)$, $124.1\left(\mathrm{~d},{ }^{4} \mathrm{JPC}=1.9 \mathrm{~Hz}, \mathrm{HC}=\mathrm{CHNCH}_{2}\right), 119.9\left(\mathrm{~d},{ }^{3} \mathrm{JPC}=3.8 \mathrm{~Hz}\right.$, $\left.\mathrm{HC}=\mathrm{CHNCH}_{2}\right), 60.6\left(\mathrm{~d},{ }^{3} \mathrm{JPC}=3.7 \mathrm{~Hz}, \mathrm{CH}_{2}\right), 35.5\left(\mathrm{~d},{ }^{3} \mathrm{JCH}_{\mathrm{CH}}=12.8 \mathrm{~Hz}, \mathrm{CH}_{3}\right)$ - IR: $\tilde{v}=3099(\mathrm{~m}), 2970(\mathrm{w}), 1558(\mathrm{~m}), 1464(\mathrm{~m}), 1442(\mathrm{w}), 1413(\mathrm{~m})$ $1341(\mathrm{~m}), 1391(\mathrm{~m}), 1266(\mathrm{~m}), 1225(\mathrm{w}), 1196(\mathrm{~s}), 1104(\mathrm{~m}), 1046(\mathrm{w})$, $815(\mathrm{~m}) 759$ (s), $718(\mathrm{~s}), 664(\mathrm{~s}), 651(\mathrm{~m}) .-\mathrm{C}_{9} \mathrm{H}_{12} \mathrm{IN}_{4} \mathrm{P}$ (334.10): calcd C 32.36 N 16.77 H 3.62 found: C 32.33 N 16.81 H 3.61 .

Synthesis of $8 b[\mathrm{Br}]$ : The reaction of $4 \mathrm{~b}[\mathrm{Br}]_{2}(5.00 \mathrm{~g}, 14.2 \mathrm{mmol})$, $\mathrm{KOtBu}(3.19 \mathrm{~g}, 28.4 \mathrm{mmol})$ and $\mathrm{P}_{4}(2.20 \mathrm{~g}, 17.8 \mathrm{mmol})$ was carried out in the same manner as described above to yield $1.50 \mathrm{~g}(4.97 \mathrm{mmol}$, yield $35 \%$ with respect to $\left.4 \mathrm{~b}[\mathrm{Br}]_{2}\right)$ of $8 \mathrm{~b}[\mathrm{Br}]$ as colorless, crystalline solid. Single crystals suitable for an XRD study were obtained from a concentrated acetonitrile solution. $-{ }^{1} \mathrm{H}$ NMR $\left(400 \mathrm{MHz}, \mathrm{CD}_{2} \mathrm{Cl}_{2}\right): \delta=7.52$ (br s, $2 \mathrm{H}, \mathrm{HC}=\mathrm{CHNCH}_{2}$ ), 7.11 (br s, $\left.2 \mathrm{H}, \mathrm{HC}=\mathrm{CHNCH}_{2}\right), 4.72(\mathrm{~s}, 4 \mathrm{H}$, $\left.\mathrm{CH}_{2}\right), 3.59\left(\mathrm{~s}, 6 \mathrm{H}, \mathrm{CH}_{3}\right) .-{ }^{31} \mathrm{P} \mathrm{NMR}\left(161.9 \mathrm{MHz}, \mathrm{CD}_{2} \mathrm{Cl}_{2}\right): \delta=-81.4 .-$ ${ }^{13} \mathrm{C}\left\{{ }^{1} \mathrm{H}\right\}$ NMR $\left(100.5 \mathrm{MHz}, \mathrm{CD}_{2} \mathrm{Cl}_{2}\right): \delta=158.1\left(\mathrm{~d},{ }^{1} \mathrm{PCC}=83.8 \mathrm{~Hz}, \mathrm{PC}\right)$, $122.9\left(\mathrm{~d},{ }^{3} \mathrm{JPC}_{\mathrm{PC}}=4.5 \mathrm{~Hz}, \mathrm{HC}=\mathrm{CHNCH}_{2}\right), 122.1\left(\mathrm{~s}, \mathrm{HC}=\mathrm{CHNCH}_{2}\right), 50.9$ (s, $\left.\mathrm{CH}_{2}\right), 35.7\left(\mathrm{~d},{ }^{3} \mathrm{JPC}_{\mathrm{PC}}=22.6 \mathrm{~Hz}, \mathrm{CH}_{3}\right) .-{ }^{1} \mathrm{H}$ NMR $\left(250 \mathrm{MHz}, \mathrm{CDCl}_{3}\right): \delta=$ $7.53\left(\mathrm{dd}, 2 \mathrm{H},{ }^{4} \mathrm{JPH}_{\mathrm{PH}}=2.3 \mathrm{~Hz},{ }^{3} \mathrm{JHH}_{\mathrm{HH}}=1.3 \mathrm{~Hz}, \mathrm{HC}=\mathrm{CHNCH}_{2}\right), 7.06(\mathrm{t}, 2 \mathrm{H}$, $\left.{ }^{3} J_{\mathrm{HH}}={ }^{4} \mathrm{JPH}_{\mathrm{PH}}=2.3 \mathrm{~Hz}, \mathrm{HC}=\mathrm{CHNCH}_{2}\right), 4.79\left(\mathrm{~s}, 4 \mathrm{H}, \mathrm{CH}_{2}\right), 3.60\left(\mathrm{~d}, 6 \mathrm{H},{ }^{4} \mathrm{JPH}_{\mathrm{PH}}\right.$ $\left.=2.0 \mathrm{~Hz}, \mathrm{CH}_{3}\right) .-{ }^{31} \mathrm{P}$ NMR $\left(101.2 \mathrm{MHz}, \mathrm{CDCl}_{3}\right): \delta=-80.8 .-{ }^{13} \mathrm{C}\left\{{ }^{1} \mathrm{H}\right\}$ $\operatorname{NMR}\left(62.8 \mathrm{MHz}, \mathrm{CDCl}_{3}\right): \delta=157.5\left(\mathrm{~d},{ }^{1} \mathrm{JPC}=83.8 \mathrm{~Hz}, \mathrm{PC}\right), 123.1\left(\mathrm{~d},{ }^{3} \mathrm{JPC}\right.$ $\left.=4.5 \mathrm{~Hz}, \mathrm{HC}=\mathrm{CHNCH}_{2}\right), 121.8\left(\mathrm{~s}, \mathrm{HC}=\mathrm{CHNCH}_{2}\right), 50.9\left(\mathrm{~s}, \mathrm{CH}_{2}\right), 35.6(\mathrm{~d}$, $\left.{ }^{3} J_{P C}=22.6 \mathrm{~Hz}, \mathrm{CH}_{3}\right) .-\mathrm{C}_{10} \mathrm{H}_{14} \mathrm{BrN}_{4} \mathrm{P}(301.13) \cdot 0.75 \mathrm{CH}_{3} \mathrm{CN}$ : calcd $\mathrm{C}$ $41.61 \mathrm{H} 4.93 \mathrm{~N} \mathrm{20.05}$, found C $41.61 \mathrm{H} 4.96 \mathrm{~N} 19.46$. The quantity of the residual solvent was verified by ${ }^{1} \mathrm{H}$ NMR spectroscopy.
Synthesis of $10 \mathrm{a}[\mathrm{l}]$ : A $25 \mathrm{ml}$ round-bottom Schlenk-flask was loaded with $8 \mathrm{a}[\mathrm{l}](50.0 \mathrm{mg}, 0.15 \mathrm{mmol})$ and $\mathrm{I}_{2}(38 \mathrm{mg}, 0.15 \mathrm{mmol})$. The flask was cooled to $-78{ }^{\circ} \mathrm{C}$ and the solids dissolved by addition of $\mathrm{CH}_{2} \mathrm{Cl}_{2}(10 \mathrm{ml})$. The solution, which had adopted a red color, was stirred for $1 \mathrm{~h}$ at $-78{ }^{\circ} \mathrm{C}$ and then allowed to warm slowly to room temperature while stirring was continued. An orange precipitate was separated by filtration and washed with ice cold $\mathrm{CH}_{2} \mathrm{Cl}_{2}(2 \times 2 \mathrm{ml})$. The filtrate was evaporated to dryness, the remaining orange solid dissolved in $\mathrm{CH}_{3} \mathrm{CN}(50 \mathrm{ml})$, and the resulting suspension filtered over celite. Removal of the solvent from the filtrate under reduced pressure afforded $80.2 \mathrm{mg}(0.14 \mathrm{mmol}$, yield $91 \%)$ of 10a[I]. Dark red crystals suitable for a XRD study were obtained from a concentrated solution in $\mathrm{CH}_{3} \mathrm{CN} .-{ }^{1} \mathrm{H}$ NMR $(400 \mathrm{MHz}): \delta=7.75(\mathrm{~m}, 2 \mathrm{H}$, $\left.\mathrm{HC}=\mathrm{CHNCH}_{2}\right), 7.64\left(\mathrm{t}, 2 \mathrm{H},{ }^{4} \mathrm{JPH}={ }^{3} \mathrm{~J}_{\mathrm{HH}}=2.4 \mathrm{~Hz}, \mathrm{HC}=\mathrm{CHNCH}_{2}\right), 6.73(\mathrm{~d}$, $\left.1 \mathrm{H},{ }^{2} \mathrm{JHH}_{\mathrm{HH}}=14 \mathrm{~Hz}, \mathrm{CH}_{2}\right), 6.53\left(\mathrm{~d}, 1 \mathrm{H},{ }^{2} \mathrm{JHH}=14 \mathrm{~Hz}, \mathrm{CH}_{2}\right), 3.81(\mathrm{~s}, 6 \mathrm{H}$, $\left.\mathrm{CH}_{3}\right) .-{ }^{31} \mathrm{P}$ NMR $(101.2 \mathrm{MHz}): \delta=-146.8 .-{ }^{13} \mathrm{C}\left\{{ }^{1} \mathrm{H}\right\} \mathrm{NMR}(62.8 \mathrm{MHz}): \delta$ $=145.7\left(\mathrm{~d},{ }^{1} \mathrm{~J}_{\mathrm{CP}}=110 \mathrm{~Hz}, \mathrm{C}=\mathrm{P}\right), 125.1\left(\mathrm{~d},{ }^{3} \mathrm{~J}_{\mathrm{CH}}=4.6 \mathrm{~Hz}, \mathrm{HC}=\mathrm{CHNCH}_{2}\right)$, $123.7\left(\mathrm{~d},{ }^{3} \mathrm{JPC}_{\mathrm{PC}}=3.8 \mathrm{~Hz}, \mathrm{HC}=\mathrm{CHNCH}_{2}\right), 61.1\left(\mathrm{~s}, \mathrm{CH}_{2}\right), 37.5\left(\mathrm{~s}, \mathrm{CH}_{3}\right)$. $\left.\mathrm{C}_{9} \mathrm{H}_{12}\right|_{3} \mathrm{~N}_{4} \mathrm{P}(587.91)$ : calcd C $18.39 \mathrm{~N} 2.06 \mathrm{H}$ 9.53, found C 18.70, H 2.08 N 9.50 .

Synthesis of $10 \mathrm{~b}[\mathrm{l}]$ : The reaction of $8 \mathrm{~b}[\mathrm{Br}](50.0 \mathrm{mg}, 0.17 \mathrm{mmol})$ and $\mathrm{I}_{2}(42.1 \mathrm{mg}, 0.17 \mathrm{mmol})$ was carried out as described for $10 \mathrm{a}[\mathrm{l}]$ to furnish $81.0 \mathrm{mg}$ of a reddish solid addressed as $10 \mathrm{~b}[\mathrm{Br}](15 \mathrm{mmol}$, yield $88 \%)$. Fractional recrystallization from a concentrated solution in $\mathrm{CH}_{3} \mathrm{CN}$ furnished a crop of dark red crystals which were used for analytical and spectroscopic characterization and a single-crystal XRD study and identified as a solvate of composition $10 \mathrm{~b}[\mathrm{l}] \cdot \mathrm{CH}_{3} \mathrm{CN}$. $-{ }^{1} \mathrm{H}$ NMR $(250$ $\mathrm{MHz}): \delta=7.66\left(\mathrm{dd}, 2 \mathrm{H},{ }^{4} \mathrm{JPH}_{\mathrm{PH}}=1.1 \mathrm{~Hz},{ }^{3} \mathrm{~J}_{\mathrm{HH}}=1.9 \mathrm{~Hz}, \mathrm{HC}=\mathrm{CHNCH}_{2}\right)$, $7.55\left(\mathrm{dd}, 2 \mathrm{H},{ }^{4} \mathrm{JPH}=4.1 \mathrm{~Hz},{ }^{3} \mathrm{JHH}_{\mathrm{HH}}=1.9 \mathrm{~Hz}, \mathrm{HC}=\mathrm{CHNCH}_{2}\right), 4.89(\mathrm{~s}, 4 \mathrm{H}$, $\mathrm{CH}_{2}$ ), 3.88 (br s, $\left.6 \mathrm{H}, \mathrm{CH}_{3}\right)$. $-{ }^{31} \mathrm{P}$ NMR $(101.2 \mathrm{MHz}): \delta=-130.4$. ${ }^{13} \mathrm{C}\left\{{ }^{1} \mathrm{H}\right\}$ NMR $(62.8 \mathrm{MHz}): \delta=127.8\left(\mathrm{~s}, \mathrm{HC}=\mathrm{CHNCH}_{2}\right), 126.0(\mathrm{~s}$, $\left.\mathrm{HC}=\mathrm{CHNCH}_{2}\right), 50.5\left(\mathrm{~s}, \mathrm{CH}_{2}\right), 37.3\left(\mathrm{~d},{ }^{3} \mathrm{JPC}=13 \mathrm{~Hz}, \mathrm{CH}_{3}\right) .-\mathrm{IR}: \tilde{v}=3084$ $(\mathrm{m}), 2963(\mathrm{~m}), 2247(\mathrm{w}, \mathrm{MeCN}), 1558(\mathrm{~m}), 1500(\mathrm{~m}) 1489(\mathrm{~m}), 1439(\mathrm{w})$, $1409(\mathrm{~m}), 1361(\mathrm{w}), 1347(\mathrm{w}), 1255(\mathrm{~m}), 1215(\mathrm{~m}), 1149(\mathrm{w}), 1089(\mathrm{~b})$, 1031 (b), 761 (s), 744 (s), 724 (s), 669 (s). $\quad-\quad \mathrm{C}_{10} \mathrm{H}_{14} \mathrm{l}_{3} \mathrm{~N}_{4} \mathrm{P}$ (554.93) $\mathrm{CH}_{3} \mathrm{CN}$ : calcd C $22.42 \mathrm{H} 2.66 \mathrm{~N} 10.89$, found C $22.59 \mathrm{H} 2.79 \mathrm{~N}$ 10.79. The quantity of the residual solvent was verified by ${ }^{1} \mathrm{H}$ NMR spectroscopy.

\section{Crystallographic studies}

Single X-ray diffraction data of $8 \mathrm{a}[\mathrm{l}], \mathbf{8 b}[\mathrm{Br}], \mathbf{1 0 a}[\mathrm{l}]$, and $\mathbf{1 0 b}[\mathrm{I}]$ were measured with a Bruker Kappa Apex2 Duo diffractometer using Mo-Ka radiation $(\lambda=0.71073 \AA)$ at $130(2) \mathrm{K}(8 \mathrm{a}[\mathrm{l}], \mathbf{8 b}[\mathrm{Br}], 10 \mathrm{a}[\mathrm{l}])$ or $150(2) \mathrm{K}$ $(\mathbf{1 0 b}[\mathrm{I}])$. Crystals were selected under Formblin $Y$ perfluoro-oil, mounted on a nylon loop, and immediately placed in a cold stream of $\mathrm{N}_{2}$. The structures were solved by direct methods (SHELXS-2014 [19]) and refined with a full-matrix least-squares scheme on $F^{2}$ (SHELXL-2014 [19]). A numerical absorption correction from equivalents was applied. Nonhydrogen atoms were refined anisotropically and hydrogen atoms with a riding model. Structure $10 \mathrm{~b}[\mathrm{l}]$ showed irregular anisotropic displacement parameters for the atoms 13 and 16 which arises from mixed occupation of these sites by iodine and a small amount of bromine atoms which could not be successfully resolved. One of the solvent molecules in $10 \mathrm{~b}[\mathrm{l}]$ is disordered over two positions. Further crystallographic data and details on the structure solution are given in Table S1. CCDC 1848835 1848838 contain the supplementary crystallographic data for this work. These data can be obtained free of charge from the Cambridge Crystallographic Data Centre via www.ccdc.cam.ac.uk/data_request/cif.

\section{Computational studies}

All computational studies were carried out on the bwForCluster Justus. RI-DFT calculations for energy optimization of the molecular structures of 2a-d and 4d were carried out with the TURBOMOLE program suite [20] using the B3LYP functional [21] with a def2-tzvp basis set. ${ }^{[22]}$ Grimme's 
D3BJ formalism [23] was used to include dispersion effects and solvation effects were simulated by the conductor-like screening model ${ }^{[24]}$ with the solvent parameters for acetonitrile. The same approach had recently been employed for a computational characterization of 5.[10] Molecular structures were identified as local minima on the energy hypersurface by harmonic vibrational frequency calculations. The energies at the stationary points were recalculated at the B3LYP/def2-tzvp level (including Grimme's D3BJ formalism [23] for an empirical dispersion correction and simulating solvation effects with a PCM model (SCRF(solvent=acetonitrile)) using the Gaussian16 [25] program suite. Natural population analysis ${ }^{[17]}$ of the resulting densities was performed with the NBO module implemented in the Gaussian software.

\section{Acknowledgements}

The authors thank Dr. Wolfgang Frey (Institute of Organic Chemistry, University of Stuttgart) for the collection of X-ray diffraction data and acknowledge support by the state of BadenWürttemberg through bwHPC and the German Research Foundation (DFG) through grants no INST 40/467-1 FUGG and Gu 415/17-1.

Keywords: Phosphorus • Phosphamethine cyanines • Nitrogen heterocycles $\cdot$ Halogenation $\bullet$ Charge transfer

[1] K. Dimroth, P. Hoffmann, Angew. Chem. 1964, 76, 433-433; Angew. Chem. Int. Ed. Engl. 1964, 3, 384-384.

[2] a) A. Schmidpeter, S. Lochschmidt, A. Willhalm, Angew. Chem. 1983 95, 561-562; Angew. Chem., Int. Ed. Engl. 1983, 22, 545-546.

[3] B. D. Ellis, C. A. Dyker, A. Decken, C. L. B. Macdonald, Chem. Commun. 2005, 1965-1967.

[4] A. Schmidpeter, in Multiple Bonds and Low Coordination in Phosphorus Chemistry (Eds.: M. Regitz, O. J. Scherer), Thieme, Stuttgart, 1990, pp. 149-154.

[5] M. Cicač-Hudi, J. Bender, S. H. Schlindwein, M. Bispinghoff, M. Nieger, H. Grützmacher, D. Gudat, Eur. J. Inorg. Chem. 2016, 649-658.

[6] J. F. Binder, A. Swidan, M. Tang, J. H. Nguyen, C. L. B. Macdonald, Chem. Commun., 2015, 51, 7741-7744.

[7] C. L. B. Macdonald, J. F. Binder, A. Swidan, J. H. Nguyen, S. C. Kosnik, B. D. Ellis, Inorg. Chem. 2016, 55, 7152-7166.

[8] J. F. Binder, S. C. Kosnik, C. L. B. Macdonald, Chem. Eur. J. 2018, 24, 3556-3565.

[9] J. F. Binder, A. M. Corrente, C. L. B. Macdonald, Dalton Trans, 2016, $45,2138-2147$.
[10] M. Cicač-Hudi, S. H. Schlindwein, C. M. Feil, M. Nieger, D. Gudat, Chem. Commun. 2018, DOI: 10.1039/C8CC03972K.

[11] T. Böttcher, S. Steinhauer, L. C. Lewis-Alleyne, B. Neumann, H.-G Stammler, B. S. Bassil, G.-V. Röschenthaler, B. Hoge, Chem. Eur. J 2015, 21, $893-899$.

[12] K. Schwedtmann, M. H. Holthausen, K.-O. Feldmann, J. J. Weigand, Angew. Chem. Int. Ed. 2013, 52, 14204-14208.

[13] S.Alvarez, Dalton Trans. 2013, 42, 86178636

[14] F. H. Allen, O. Kennard, D. G. Watson, L. Brammer, A. G. Orpen, R. Taylor, J. Chem. Soc. Perkin Trans. II, 1987, S1-S83.

[15] a) C. Maaliki, C. Lepetit, Y. Canac, C. Bijani, C. Duhayon, R. Chauvin, Chem. Eur. J. 2012, 18, 7705-7714; b) A. M. Makaya, Y. Canac, C. Bijani, C. Duhayon, R. Chauvin, Phosphorus, Sulfur, Silicon 2015, 190 789-802;

[16] C. Maaliki, Y. Canac, C. Lepetit, C. Duhayon, R. Chauvin, RSC Adv. 2013, 3, 20391-20398; b) M. Mehta, T. C. Johnstone, J. Lam, B. Bagh A. Hermannsdorfer, M. Driess, D. W. Stephan, Dalton Trans. 2017, 46, 14149-14157.

[17] A. E. Reed, R. B. Weinstock, F. Weinhold, J. Chem. Phys. 1985, 83, 735-746.

[18] S. Bai, C. Bu, Q. Tai, L. Liang, Y. Liu, S. You, Z. Yu, S. Guo, X. Zhao, ACS Appl. Mater. Interfaces 2013, 5, 3356-3361.

[19] a) M. Sheldrick, Acta Crystallogr., Sect. C 2015, 71, 3-8; b) G. M. Sheldrick, Acta Crystallogr., Sect. A 2008, 64, 112-122.

[20] TURBOMOLE V7.2 2017, a development of University of Karlsruhe and Forschungszentrum Karlsruhe $\mathrm{GmbH}$, 1989-2007, TURBOMOLE $\mathrm{GmbH}$, since 2007; available from http://www.turbomole.com.

[21] A. D. Becke, J. Chem. Phys. 1993, 98, 5648-5652.

[22] F. Weigend, R. Ahlrichs, Phys. Chem. Chem. Phys. 2005, 7, $3297-$ 3305

[23] S. Grimme, S. Ehrlich, L. Goerigk, J. Comp. Chem. 2011, 32, 14561465

[24] A. Klamt, G. Schüürmann, J. Chem. Soc. Perkin Trans. 1993, 2, 799805.

[25] Gaussian 16, Revision B.01, M. J. Frisch, G. W. Trucks, H. B. Schlegel, G. E. Scuseria, M. A. Robb, J. R. Cheeseman, G. Scalmani, V. Barone, G. A. Petersson, H. Nakatsuji, X. Li, M. Caricato, A. V. Marenich, J. Bloino, B. G. Janesko, R. Gomperts, B. Mennucci, H. P. Hratchian, J. V. Ortiz, A. F. Izmaylov, J. L. Sonnenberg, D. Williams-Young, F. Ding, F. Lipparini, F. Egidi, J. Goings, B. Peng, A. Petrone, T. Henderson, D Ranasinghe, V. G. Zakrzewski, J. Gao, N. Rega, G. Zheng, W. Liang, M. Hada, M. Ehara, K. Toyota, R. Fukuda, J. Hasegawa, M. Ishida, T. Nakajima, Y. Honda, O. Kitao, H. Nakai, T. Vreven, K. Throssell, J. A Montgomery, Jr., J. E. Peralta, F. Ogliaro, M. J. Bearpark, J. J. Heyd, E. N. Brothers, K. N. Kudin, V. N. Staroverov, T. A. Keith, R. Kobayashi, J. Normand, K. Raghavachari, A. P. Rendell, J. C. Burant, S. S. lyengar, J. Tomasi, M. Cossi, J. M. Millam, M. Klene, C. Adamo, R. Cammi, J. W. Ochterski, R. L. Martin, K. Morokuma, O. Farkas, J. B. Foresman, and D. J. Fox, Gaussian, Inc., Wallingford CT, 2016. 
Entry for the Table of Contents (Please choose one layout)

Layout 1:

\section{FULL PAPER}

Tricyclic bis-imidazolio-phosphanide halides accessed from white phosphorus and bis-imidazolium salts undergo iodination to afford bisimidazolio-diiodophosphoranide iodides. The products can be described as charge-transfer complexes of dicationic iodophosphines with iodide.
M. Cicač-Hudi, S. H. Schlindwein, C. M. Feil, M. Nieger, and Dietrich Gudat*

Page No. - Page No.

Cationic diiodo-phosphoranides through oxidative $\mathrm{I}_{2}$ addition to tricyclic phosphamethine cyanines 
Additional Author information for the electronic version of the article.

Dietrich Gudat:

Martin Nieger:

0000-0002-9196-0466

Author: 